\title{
Effects of L2 usage and L1 transfer on Turkish learners' production of English verb-argument constructions
}

Ute Römer

Georgia State University, USA

uroemer@gsu.edu

Selahattin Yilmaz

Georgia State University, USA

syilmaz2@gsu.edu

\begin{abstract}
Using data from the International Corpus of Learner English (ICLE) and the British National Corpus (BNC), this article examines what Turkish learners of English know about a set of frequent verb-argument constructions (VACs, such as 'V with n' as illustrated by 'I like to go with the flow') and in what ways their VAC knowledge is influenced by native English usage and by transfer from their first language (L1), Turkish. An ICLE Turkish analysis gave us access to dominant verb-VAC associations in Turkish learners' English, and provided insights into the productivity and predictability of selected constructions. Comparisons with the BNC and other ICLE subsets (ICLE German and ICLE Spanish) allowed us to determine how strong the usage effect is on Turkish learners' verb-VAC associations and whether Turkish learners differ in this respect from learners of other typologically different L1s. Potential effects of L1 transfer were explored with the help of a large reference corpus of Turkish, the Turkish National Corpus (TNC).
\end{abstract}

Keywords: Construction Grammar, verb-argument constructions, learner corpus; usage-based SLA, crosslinguistic transfer

\section{Zusammenfassung}

Dieser Aufsatz untersucht basierend auf Daten aus dem International Corpus of Learner English (ICLE) und dem British National Corpus (BNC), was türkische Lernerinnen und Lerner des Englischen über eine Auswahl von Verb-Argument Konstruktionen (VACs, z. B. 'V with n' illustriert durch 'I like to go with the flow') wissen und welchen Einfluss englischer Sprachgebrauch und Erstsprache auf dieses Wissen haben. Eine Analyse von Daten aus dem türkischen Teil von ICLE (ICLE Turkish) ermöglichte 
uns Zugang zu besonders dominanten Verb-VAC Assoziationen in türkischem LernerInnenenglisch sowie Einsicht in die Produktivität und Voraussagbarkeit verschiedener Konstruktionen. Durch Vergleiche mit dem BNC und anderen Teilen von ICLE (ICLE German und ICLE Spanish) konnten wir bestimmen, wie stark der Sprachgebrauchseffekt auf die Verb-VAC Assoziationen türkischer Lernerinnen und Lerner ist und ob es diesbezüglich Unterschiede zwischen türkischen Lernerinnen und Lernern und Lernerinnen und Lernern anderer typologisch unterschiedlicher Sprachhintergründe gibt. Mögliche interlinguale Interferenzeffekte wurden mit Hilfe eines umfangreichen türkischen Referenzkorpus, dem Turkish National Corpus (TNC), untersucht.

Schlüsselwörter: Konstruktionsgrammatik, Verb-Argument Konstruktionen, Lernerkorpus, gebrauchsbasierter Zweitspracherwerb, interlinguale Interferenz

\section{Introduction}

Research within the framework of Construction Grammar suggests that learning languages requires building a network of constructions, that is, conventionalized formfunction associations, which can differ greatly from one language to another (Goldberg, 2006; Goldberg \& Casenhiser, 2008; Hilpert, 2014). Specifically, verb-argument constructions (VACs) have received a great deal of attention as they are considered the "basic means of clausal expression in a language" (Goldberg, 1995: 3). For second language (L2) learners, typological differences between their first and second language may pose a challenge to their learning of constructions in the target language. Recent research on VACs in the language of advanced L2 learners of English of different first language (L1) backgrounds, for instance, shows that L1 Spanish learners produce VACs including 'verb plus preposition plus noun (phrase)' constructions (e.g. 'V over n' exemplified by 'she jumped over the fence') with less target-like verbs than L1 German and L1 Czech learners at the same proficiency level (Ellis, O'Donnell \& Römer, 2014; Römer, O’Donnell \& Ellis, 2014). This especially applies to the production of directed motion constructions which are realized differently in verb-framed and satellite-framed languages (Cadierno, 2008, 2013; Slobin, 2004; Talmy, 2000). While a verb-framed language such as Spanish or Italian expresses the path of motion in the main verb (e.g. saltar in Spanish), a satellite-framed language such as English or German expresses the path of motion in a separate particle (the satellite) and manner in the main verb (e.g. jump over in English). To help learners of typologically different L1s in their acquisition of English, it is hence important to better understand these learners' knowledge of VACs and examine which verbs they most commonly associate with a particular construction. 
Studies that have examined VACs in learner production data, both collected from learner corpora and in psycholinguistic experiments, have indicated that (i) L2 learners, especially at intermediate and advanced levels of proficiency, possess verbconstructional knowledge, that (ii) learners' VAC production is affected by verb frequencies in usage (the target language input they receive), that (iii) there is significant overlap between learners' and native speakers' verb-VAC associations, and that (iv) differences in VAC usage between L1 and L2 speakers can be explained on the basis of crosslinguistic transfer effects from the learners' first language (Ellis \& Ferreira-Junior, 2009; Ellis, O’Donnell \& Römer, 2014; Ellis, Römer \& O’Donnell, 2016; Eskildsen \& Cadierno, 2007; Römer \& Garner, under review; Römer, O’Donnell \& Ellis, 2014; Römer, Roberson, O’Donnell \& Ellis, 2014; Römer, Skalicky \& Ellis, 2018). These studies have focused on English language learners from a range of L1 backgrounds, including Czech, German, Italian, and Spanish.

However, to our knowledge, there are no related studies on L1 Turkish learners' productive knowledge of English VACs (with the recent exception of Babanollu 2018), or studies that compare constructions in Turkish learners with those produced by learners from other L1 backgrounds. Given the typological properties of Turkish verb morphology (further described in Section 2), VACs that encode directed motion and include prepositions can be particularly difficult to acquire for Turkish learners. The goal of this article is therefore to use data from a corpus of L1 Turkish learner writing to gain a better understanding of what intermediate to advanced Turkish learners of English know about a subset of frequent VACs of the 'verb plus preposition plus noun (phrase)' type, and whether/how this knowledge is affected by L2 (target language) usage and by L1 transfer (Gass \& Selinker, 1983; Jarvis, 2011, 2013; Jarvis \& Pavlenko, 2008). The research questions we aim to address are:

RQ 1: How productive and how predictable are selected VACs in Turkish learner English compared to German and Spanish learner English?

RQ 2: In terms of dominant verb-VAC associations, do selected VACs in Turkish learner English differ from those in German and Spanish learner English? If so, in what ways?

RQ 3: Is the distribution of verbs in a set of high-frequency VACs in Turkish learner English influenced by English usage? Is this potential influence of usage stronger for Turkish than for German and Spanish learners?

RQ 4: Are there any noticeable effects of the first language on Turkish learners' use of English VACs? 
Before we describe how these research questions are addressed methodologically, and what answers our analyses provide in response to them, we will provide some information on typological aspects of the Turkish language. This information offers the necessary background for our discussion of L1 Turkish learners' productive knowledge of English VACs and how it may be affected by crosslinguistic transfer.

\section{Properties of verb constructions in Turkish}

In Turkish, a verb-framed language, the path of motion is expressed within the verb, while manner is expressed separately and usually given less focus (Slobin, 2014). This typological difference leads to a less frequent expression of manner unless it is "the salient information in the discourse context" (Özyürek \& Kita, 1999: 507). For example, the Turkish equivalents of climb up (trman-) and go down (in-) focus on the path expressed in the main verb with manner being of secondary importance. However, Jessen (2014) notes that Turkish is different from most verb-framed languages in that path can also be expressed using other items, sometimes in combination with the main verb, such as nominals, adpositions (prepositions or postpositions), and case marking. Both Özyürek and Özçalışkan (2000) and Jensen (2004) also comment that L1 Turkish speakers may describe a motion event by using two verbal clauses, the first one being the subordinate clause that expresses manner, the second one being the matrix clause expressing path. For instance, in order to express crawl up, an L1 Turkish speaker is most likely to say ascend by crawling (emekleyerek çı-). Therefore, highlighting the different ways of expressing motion, Beavers, Levin, and Tham (2010) claim that it is hard to speak of a two-way typology with clear boundaries between the two.

Comparative research on the verbal expression of motion by L1 Turkish and English speakers has shown that these typological differences between the two languages lead to differences in the use and frequency of manner and path (Jessen, 2014, Özyürek \& Kita, 1999; Özyürek \& Özçalışkan, 2000; Özyürek, Kita, Allen, Furman \& Brown, 2008; Slobin, 2004; Toplu, 2011). Nevertheless, much as these typological differences play a large role, there are also certain universals of expressing motion such as merging path and manner (Allen, Özyürek, Kita, Brown, Furman, Ishizuka, Fujii, 2007) and manner-dominant conceptualization of motion regardless of languages (Toplu, 2011).

Most of this comparative Turkish-English research made use of verbal production tasks that required the participants who were advanced learners to respond to audiovisual cues. In their bilingual production studies (L1 Turkish, L2 English), Demirtaş (2010) and D. Yilmaz (2018) showed that advanced Turkish learners were able to use manner verbs and path satellites to a great extent with only limited L1 influence such as using subordinating elements and avoiding the use of verbs that do not 
express motion in Turkish. However, interestingly, the L1 Turkish production of the participants was found to include frequent use of manner verbs, which both authors attributed to the influence of the L2 (English) on the L1. Durun (2015) and Duruk (2016) also reported a similar finding on advanced Turkish learners, namely that they used path satellites very commonly like L2 English speakers with a limited amount of L1 influence affecting the use of path-dominant verbs (e.g. ENTER, CROSs). Looking at task and proficiency factors as well as L1 influence, İşler (2014), however, found that the participants' L1 led to limited use of path elements in general. While proficiency positively correlated with path expression in the results of the written task, gestures seemed to have played a much more important role in expressing path in spoken production.

In a study based on learner production data, Babanoğlu (2018) investigated the use of manner of motion verbs (e.g. WALK, RUN, FLY) and path verbs (e.g. ENTER, PASS, ARRIVE) across the L1 German and L1 Turkish subsets of ICLE. The study showed that L1 Turkish writers used both path and manner verbs significantly less than the German writers did. It also showed that the German writers made use of a remarkably higher use of satellites to express path especially with the verb RUN.

In addition to these typological aspects that affect the expression of motion, it is important to mention some general complexities of Turkish morphology. As documented by Durrant (2013), morphemic co-occurrences are much stronger in Turkish than lexical ones, which makes this a distinctive feature of constructional patterns in Turkish. In addition, English prepositions are known to pose difficulties for even advanced learners independent of the L1 background. English as a Lingua Franca (ELF) research has documented non-conventional uses of prepositions in contexts where English is used for oral communication by speakers of different L1s (Cogo \& Dewey, 2010; Seidlhofer, 2004). Due to the combined influence of complex morphology in general (Durrant, 2013) and of expressing motion in particular (Jensen, 2014; Özyürek \& Çalışkan, 2000), Turkish learners could have particularly marked challenges. For example, Çabuk (2009) and Özışık's (2014) analyses of the use of prepositions in Turkish learner English showed that Turkish learners tend to rely on L1 transfer, thus using prepositions that are similar to their L1, however mostly erroneously, such as marry with someone instead of marry someone. They also observe an overuse of the preposition in by Turkish learners. Likewise, differences between the two languages were found to pose challenges for learners of Turkish as a foreign language because of the multi-layered morphology (Özdemir, 2011). Thus, analyses of 'verb plus preposition plus noun (phrase)' constructions could shed light on several aspects of L1 influence on the L2 usage of Turkish learners. 


\section{Data and methods}

To address our research questions, we collected VAC data from the Turkish subsection of the International Corpus of Learner English (ICLE Turkish; Granger et al., 2009). ICLE Turkish consists of argumentative essays written by intermediate to advanced level EFL learners who were undergraduate students majoring in English at three universities in southern Turkey. Overall ICLE Turkish contains 280 texts and 199,173 words. We also used data from previous analyses of VACs in L1 German and L1 Spanish learner writing and in native English usage. The learner writing for these analyses came from the German and Spanish subcomponents of ICLE (henceforth ICLE German and ICLE Spanish), whereas the 100-million-word British National Corpus (BNC; Burnard, 2007) served as a proxy for L1 English usage. In terms of text type and size, ICLE German (236,095 words) and ICLE Spanish (198,109 words) are comparable to ICLE Turkish. However, while the German learners who contributed to ICLE are mostly at advanced (C1) proficiency level, Turkish and Spanish texts in ICLE come from learners at intermediate and advanced levels (B1 to C1).

In addition to the L1 and L2 English language data, we also retrieved data from the Turkish National Corpus (TNC; Aksan \& Aksan, 2009). The TNC is a 50 millionword general corpus of Turkish that includes mostly written data (98\%) from a wide variety of genres ranging from scientific texts to fiction produced between 1990 and 2009. Modeled after the BNC and claiming a high degree of representativeness in terms of coverage, the corpus includes a proportional amount of texts from different domains and topics (Aksan, Aksan, Koltuksuz, Sezer, Mersinli, Demirhan, Yllmazer, Kurtoğlu, Atasoy, Öz, \& Yıldız, 2012).

From ICLE Turkish, we exhaustively retrieved instances of the following 19 VACs, all covered in previous VAC analyses (Ellis, O'Donnell \& Römer, 2014; Römer, Roberson, O'Donnell \& Ellis, 2014) and originally selected from the COBUILD Grammar Patterns volume on verbs (Francis, Hunston \& Manning, 1996): 'V about n', 'V across n', 'V after n', 'V against n', 'V among n', 'V around n', 'V as n', 'V between n', 'V for n', 'V in n', 'V into n', 'V like n', 'V of n', 'V off n', 'V over n', 'V through n', 'V towards n', 'V under n', and 'V with n'. We used the search interface provided on the ICLE corpus CD-ROM to extract the selected VACs from ICLE Turkish. Since the corpus is part-of-speech tagged, we were able to search for combinations of a verb (ICLE tags Vbe, Vdo, Vhave, Vlex, Vmod) directly followed by a preposition (about, across, etc.). We exported the resulting concordances to Excel for manual filtering for true hits of each VAC. In this filtering process we made sure that, in each concordance line, the word following the verb was used as a preposition and that the preposition was followed by a noun or noun phrase. For each VAC, we then created a lemmatized, frequency-sorted list of the verbs that occur in it. 
Together with similar datasets based on ICLE German, ICLE Spanish, and the BNC that we generated in previous studies on the same VACs, the frequency-sorted ICLE Turkish verb lists served as the basis for type-token comparisons, and also as input for two types of quantitative analyses: normalized entropy analysis and correlation analysis. Normalized entropy $\left(\mathrm{H}_{\text {norm }}\right)$ is a measure of how uncertain a probability distribution is, in our case the distribution of verbs in a VAC (Kumar, Kumar \& Kapur, 1986). $H_{\text {norm }}$ values range from 0 to 1 with values closer to 1 indicating a more even distribution which makes it hard to predict what the verb in a new token of a VAC might be. On the other hand, $\mathrm{H}_{\text {norm }}$ values closer to $\mathrm{O}$ indicate an increasingly uneven and predictable distribution of items (here verbs), potentially with one or two types making up the lion's share of all tokens. Entropy has been shown to be less sensitive to Zipfian frequency patterns than type-token ratio (Eeg-Olofsson \& Altenberg, 1994; Ellis \& O'Donnell, 2014; Gries \& Ellis, 2015). The correlation analysis allowed us to systematically compare for individual VACs how strongly its verb distributions overlap or differ among learner groups (e.g. ICLE Turkish vs. ICLE German), and between a learner group and L1 usage (e.g. ICLE Turkish vs. BNC), resulting in six types of comparisons (ICLE Turkish vs. ICLE German, ICLE Turkish vs. ICLE Spanish, ICLE German vs. ICLE Spanish, ICLE Turkish vs. BNC, ICLE German vs. BNC, ICLE Spanish vs. BNC). For each comparison, we calculated Pearson correlation coefficients $(r)$ in R (R Development Core Team, 2017). We also used R to generate scatterplots that allowed us to visualize verb distributions and highlight which verbs contributed to a high or low correlation value. All calculations were based on the $\log 10$ transformations of the verb token frequencies. For selected verbs, we also carried out a more qualitative analysis of the top verb choices across datasets. Data retrieved from the TNC through concordance and collocation searches was used in tracing potential crosslinguistic transfer effects that may have had an impact on Turkish learners' verb usage in specific VACs.

\section{Results and discussion}

\subsection{Productivity and predictability of VACs in Turkish learner English}

We addressed RQ 1 by calculating type-token ratios and normalized entropy values for the selected VACs in ICLE Turkish and comparing the values with the same data retrieved for ICLE German and ICLE Spanish. Since entropy values vary across types of constructions (lower values do not always mean "better" or "more proficient"), we also calculated those for each target VAC in the BNC. The BNC values will serve as a reference point for comparison. 
Table 1 gives an overview of the type numbers, token numbers, and type-token ratios for verbs in the 19 selected VACs across ICLE subsets. The type-token ratios indicate how productive each VAC is, with higher ratios indicating higher productivity. These values, however, of course have to be treated with caution when it comes to VACs with low token frequencies. The first thing we notice is that verb type and token numbers vary considerably across VACs. For ICLE Turkish, token frequencies range from 1 instance ('V towards n') to 679 instances ('V in n'). For the majority of VACs, token frequencies are fairly low and not robust enough for more detailed quantitative analyses. In terms of type-token ratios of the higher-frequency VACs, 'V for n' and 'V with n' are more productive than 'V about n' or ' $\mathrm{V}$ in n'. This means that L1 Turkish learners use the former two constructions with a comparatively wider range of verbs than the latter two, even though ' $\mathrm{V}$ in n' is the most frequent VAC in terms of tokens and more frequent in ICLE Turkish than in ICLE German and ICLE Spanish. Of these four VACs, 'V about n' is the most selective in its verb occupancy. We notice similar trends in the ICLE German and ICLE Spanish data. In both corpora, only four out of 19 VACs are used fairly frequently, and type-token ratios are higher for ' $\mathrm{V}$ for n' and 'V with n' than for V about n' or 'V in n'. VACs tend to be comparatively more productive in ICLE Spanish than in ICLE Turkish and ICLE German. We will see later how similar or different the actual verb profiles for these constructions are across the three L1 groups. 
Table 1:.Verb type and token frequencies across VACs and ICLE subsets

\begin{tabular}{lccccccccc}
\hline & \multicolumn{3}{c}{ ICLE Turkish } & \multicolumn{3}{c}{ ICLE German } & \multicolumn{3}{c}{ ICLE Spanish } \\
VAC & Types & Tokens & TTR & Types & Tokens & TTR & Types & Tokens & TTR \\
\hline V about $\mathrm{n}$ & 31 & 209 & $14.8 \%$ & 48 & 242 & $19.8 \%$ & 42 & 178 & $23.6 \%$ \\
V across $\mathrm{n}$ & 2 & 9 & $22.2 \%$ & 6 & 9 & $66.7 \%$ & $\mathrm{~N} / \mathrm{A}$ & $\mathrm{N} / \mathrm{A}$ & $\mathrm{N} / \mathrm{A}$ \\
V after $\mathrm{n}$ & 16 & 69 & $23.2 \%$ & 4 & 15 & $26.7 \%$ & 1 & 3 & $33.3 \%$ \\
V against $\mathrm{n}$ & 7 & 17 & $41.2 \%$ & 24 & 45 & $53.3 \%$ & 13 & 61 & $21.3 \%$ \\
V among $\mathrm{n}$ & 4 & 8 & $50.0 \%$ & 4 & 5 & $80.0 \%$ & 5 & 5 & $100.0 \%$ \\
V around $\mathrm{n}$ & 9 & 12 & $75.0 \%$ & 10 & 14 & $71.4 \%$ & 10 & 15 & $66.7 \%$ \\
V as $\mathrm{n}$ & 30 & 59 & $50.8 \%$ & 30 & 56 & $53.6 \%$ & 30 & 100 & $30.0 \%$ \\
V between $\mathrm{n}$ & 13 & 15 & $86.7 \%$ & 14 & 22 & $63.6 \%$ & 11 & 19 & $57.9 \%$ \\
V for n & 87 & 243 & $35.8 \%$ & 91 & 338 & $26.9 \%$ & 78 & 258 & $30.2 \%$ \\
V in $\mathrm{n}$ & 152 & 679 & $22.4 \%$ & 165 & 556 & $29.7 \%$ & 163 & 647 & $25.2 \%$ \\
V into $\mathrm{n}$ & 11 & 35 & $31.4 \%$ & 62 & 175 & $35.4 \%$ & 25 & 55 & $45.5 \%$ \\
V like $\mathrm{n}$ & 25 & 87 & $28.7 \%$ & 1 & 1 & $100.0 \%$ & 2 & 2 & $100.0 \%$ \\
V of $\mathrm{n}$ & 26 & 105 & $24.8 \%$ & 35 & 149 & $23.5 \%$ & 44 & 100 & $44.0 \%$ \\
V off $\mathrm{n}$ & 2 & 2 & $100.0 \%$ & 19 & 32 & $59.4 \%$ & 4 & 4 & $100.0 \%$ \\
V over $\mathrm{n}$ & 12 & 16 & $75.0 \%$ & 29 & 45 & $64.4 \%$ & 6 & 6 & $100.0 \%$ \\
V through $\mathrm{n}$ & 10 & 13 & $76.9 \%$ & 26 & 40 & $65.0 \%$ & 15 & 20 & $75.0 \%$ \\
V towards $\mathrm{n}$ & 1 & 1 & $100.0 \%$ & 11 & 14 & $78.6 \%$ & 3 & 3 & $100.0 \%$ \\
V under $\mathrm{n}$ & 6 & 26 & $23.1 \%$ & 11 & 14 & $78.6 \%$ & 9 & 18 & $50.0 \%$ \\
V with $\mathrm{n}$ & 98 & 311 & $31.5 \%$ & 111 & 307 & $36.2 \%$ & 97 & 269 & $36.1 \%$ \\
\hline
\end{tabular}

In addition to measuring the productivity of VACs in learner writing, we assessed how predictable each of them is. Normalized entropy scores for each selected VAC and (sub)corpus are provided in Table 2. The lower the entropy score, the more predictable the distribution of verbs in a VAC. For VACs with token frequencies of 10 or less, we did not calculate entropies (labeled "N/A" in Table 2). We see that in native English usage, normalized entropy values for the included VACs range from 0.51 to 0.80 . Some VACs, such as ' $\mathrm{V}$ of n' or ' $\mathrm{V}$ about n', are much more predictable than others, for example ' $V$ around n' or ' $V$ over n'. Lower entropy scores tend to correspond with more Zipfian distributions in which the most frequent verb in a 
construction takes up the largest share of the VAC tokens (e.g. TALK in 'V about n'). When compared to distributions in L1 usage, VACs in learner writing as captured in ICLE are overall much less predictable. For the majority of VACs, normalized entropy values are considerably higher in ICLE Turkish/German/Spanish than in the BNC. In ICLE Turkish, values are highest for 'V around n', 'V as n', 'V between n', 'V into n', and 'V over n' which means that these VACs are particularly unpredictable, and learners may not yet have a good sense of what the preferred verbs are in these constructions. Instead learners use these VACs with a variety of verbs while not favoring particular ones. With respect to these VACs, L1 Turkish learners are also further away from the usage norm than their German and Spanish peers.

Table 2. Normalized entropy values across VACs and corpora

\begin{tabular}{lcccc}
\hline VAC & BNC & ICLE Turkish & ICLE German & $\begin{array}{c}\text { ICLE } \\
\text { Spanish }\end{array}$ \\
\hline V about $\mathrm{n}$ & 0.55 & 0.78 & 0.75 & 0.74 \\
\hline V across $\mathrm{n}$ & 0.78 & $\mathrm{~N} / \mathrm{A}$ & $\mathrm{N} / \mathrm{A}$ & $\mathrm{N} / \mathrm{A}$ \\
\hline V after $\mathrm{n}$ & 0.72 & 0.46 & 0.62 & $\mathrm{~N} / \mathrm{A}$ \\
\hline V against $\mathrm{n}$ & 0.77 & 0.76 & 0.92 & 0.68 \\
\hline V among $\mathrm{n}$ & 0.56 & $\mathrm{~N} / \mathrm{A}$ & $\mathrm{N} / \mathrm{A}$ & $\mathrm{N} / \mathrm{A}$ \\
\hline V around $\mathrm{n}$ & 0.80 & 0.97 & 0.90 & 0.94 \\
\hline V as $\mathrm{n}$ & 0.72 & 0.92 & 0.88 & 0.77 \\
\hline V between $\mathrm{n}$ & 0.73 & 0.98 & 0.91 & 0.86 \\
\hline $\mathrm{V}$ for $\mathrm{n}$ & 0.63 & 0.88 & 0.87 & 0.83 \\
\hline $\mathrm{V}$ in $\mathrm{n}$ & 0.67 & 0.74 & 0.79 & 0.79 \\
\hline V into $\mathrm{n}$ & 0.74 & 0.93 & 0.88 & 0.88 \\
\hline V like $\mathrm{n}$ & 0.57 & 0.79 & $\mathrm{~N} / \mathrm{A}$ & $\mathrm{N} / \mathrm{A}$ \\
\hline $\mathrm{V}$ of $\mathrm{n}$ & 0.51 & 0.61 & 0.71 & 0.86 \\
\hline V off $\mathrm{n}$ & 0.73 & $\mathrm{~N} / \mathrm{A}$ & 0.95 & $\mathrm{~N} / \mathrm{A}$ \\
\hline V over $\mathrm{n}$ & 0.78 & 0.96 & 0.87 & $\mathrm{~N} / \mathrm{A}$ \\
\hline V through $\mathrm{n}$ & 0.74 & 0.93 & 0.95 & 0.96 \\
\hline V towards $\mathrm{n}$ & 0.75 & $\mathrm{~N} / \mathrm{A}$ & 0.96 & $\mathrm{~N} / \mathrm{A}$ \\
\hline V under $\mathrm{n}$ & 0.61 & 0.77 & 0.96 & 0.81 \\
\hline V with $\mathrm{n}$ & 0.68 & 0.87 & 0.87 & 0.85 \\
\hline & & & &
\end{tabular}




\subsection{Dominant verb-VAC associations in Turkish learner English}

To study dominant verb-VAC associations in Turkish learner language and to determine whether they differ from those in German and Spanish learners, we only focused on VACs which had token frequencies of at least 200 in ICLE Turkish. For VACs with (often considerably) smaller token numbers we found it difficult to determine clear association patterns. This left us with four VACs for a more detailed qualitative analysis: 'V about n', 'V for n', 'V in n', and 'V with n'. For these four VACs, Table 3 lists the ten most frequent verbs in L1 usage (BNC) and in the three ICLE datasets. Verbs that appear among the top-10 in usage as well as in a learner top-10 list are italicized. For ' $V$ about n' we notice that the two verbs that appear most frequently in this construction, TALK and THINK, are shared across all four datasets. Of the other top-10 verbs in ICLE Turkish, only two (BE and KNOw) overlap with the BNC list. Additional verbs including CARE and COMPLAIN are shared with the ICLE German and ICLE Spanish lists. Two verbs that appear to be Turkish learner specific choices (at least as far as the top-10 verbs are concerned) are MENTION and DISCUss. While both are verbs that are near synonyms of the strongly attracted verb TALK, their use leads to realizations of the construction ('mention about n', 'discuss about n') that are not common in L1 usage and perhaps even considered unidiomatic. Overall, we see that Turkish learners most strongly associate verbs of communication and cognition with this VAC.

The most dominant verb associations of ' $\mathrm{V}$ for n' in ICLE Turkish are LOOK, WAIT, and $\mathrm{BE}$, all three of which also appear in the top-10 lists for the other three corpora. Not shared with any of the other top-10 verb lists for this VAC are the verbs STUDY, StRUGgle, and DO. Another item that appears among the top-10 verbs in this VAC in ICLE Turkish but is considerably more frequently used by German and Spanish learners is FIGHT. For the third focus VAC, 'V in n', the most strongly associated verbs in ICLE Turkish are BE and LIVE, both shared across all analyzed datasets. Apart from those two most frequent verbs, there is however little overlap between Turkish learner writing and L1 usage. Only wORK occurs in the ICLE Turkish top-10 and also in the three other lists. BELIEVE is shared across the three ICLE lists but does not appear among the top-10 verbs for this VAC in usage. Interestingly, the third most frequent verb in ' $\mathrm{V}$ in n' in ICLE Turkish is CHEAT - a verb that is not frequently used in this VAC in any of the other datasets. Another top-10 verb for this VAC in ICLE Turkish that does not occur among the most frequent verb choices in the other corpora is EXIST. We will examine potential reasons for the repeated use of these two verbs in Section 4.4.

For ' $\mathrm{V}$ with n', six of the top-10 most strongly associated verbs in ICLE Turkish are shared with the BNC list. They include DEAL, AGREE, LIVE, BE, COPE, and START. 
Many of these are also frequent in ICLE German and ICLE Spanish. Verbs that are specific to ICLE Turkish and are not used frequently in this VAC by the German and Spanish learners include FACE, STRUGGLE, START, CHAT, and COMPETE. If we look at similarities and differences across all three L1 groups, we notice that, for this VAC, Turkish learners' verb preferences overlap more with those of German than with those of Spanish learners. This is also reflected in the higher correlation value for the ICLE Turkish-ICLE German comparison $(r=0.65)$ provided in Table 4. For the same VAC, the correlation between ICLE Turkish and ICLE Spanish verbs is only 0.55.

The $r$-values in Table 4 also indicate that, similar to ' $V$ with n', Turkish learner's verb associations for 'V about n' are slightly closer to German $(r=0.79)$ than to Spanish learners $(r=0.76)$. The high correlation values for ' $V$ about $n$ ' suggest that all three learner groups have very similar verb associations for this VAC. For the other two highfrequency VACs in our sample, ' $V$ for n' and ' $V$ in n', correlations are stronger between ICLE Turkish and ICLE Spanish data $(r=0.71$ and $r=0.62)$ than for ICLE Turkish and ICLE German $(r=0.68$ and $r=0.59)$. Overall, we observe fairly high correlations across learner datasets for all four VACs which indicates an overall high degree of similarity in verb associations with some qualitative differences (as indicated in Table 3). Figure 1 serves to visualize this overlap in verb preferences between ICLE Turkish and ICLE German contributors for ' $\mathrm{V}$ about n'. The x-axis displays the logarithmic frequency of the verb type in 'V about n' in ICLE German; the y-axis shows the logarithmic frequency of the verb type in the same VAC in ICLE Turkish. If there were perfect overlap in verb choices between the two groups (both in terms of types and tokens), all verbs would be neatly placed along the diagonal through the middle of the plot. We see that for this comparison, this is not the case. However, most verbs appear fairly closely to the diagonal which indicates that both learner groups use them with similar token frequencies. This is also reflected in the high $r$-value of 0.79 . Verbs that appear above (and further away from) the diagonal are markedly more frequent in ICLE Turkish than in ICLE German; verbs that are plotted below the diagonal are comparatively more frequent in ICLE German than ICLE Turkish. The plot confirms our earlier observations on verbs that are shared by both learner groups (e.g. THINK, TALK, CARE), and on the verb MENTION that is particularly frequent in this VAC in ICLE Turkish but less so in ICLE German. 
Table 3. Top ten verbs for selected VACs in L1 usage and across ICLE subsets

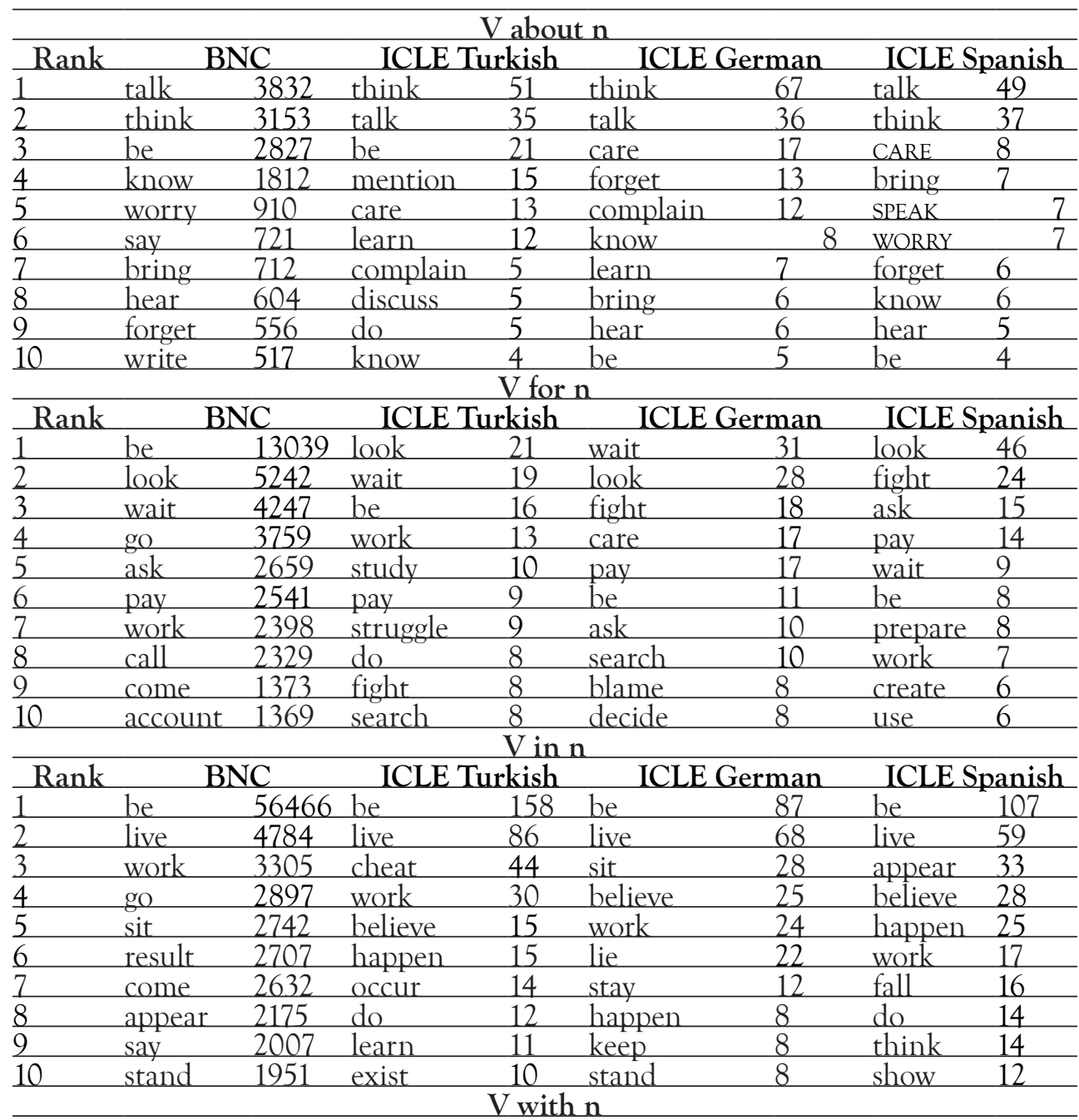

\begin{tabular}{lllllllll}
\hline \multicolumn{1}{c}{ Rank } & BNC & \multicolumn{2}{c}{ ICLE Turkish } & \multicolumn{2}{c}{ ICLE German } & \multicolumn{2}{c}{ ICLE Spanish } \\
\hline 1 & be & 8608 & deal & 32 & deal & 25 & deal & 31 \\
2 & deal & 6407 & agree & 19 & do & 20 & play & 25 \\
\hline 3 & come & 4091 & live & 18 & agree & 19 & agree & 22 \\
\hline 4 & go & 3592 & be & 14 & cope & 19 & finish & 12 \\
\hline 5 & work & 2854 & face & 13 & play & 13 & happen & 11 \\
\hline 6 & cope & 2250 & struggle & 12 & live & 10 & work & 8 \\
\hline 7 & get & 2114 & cope & 11 & work & 9 & begin & 6 \\
\hline 8 & agree & 1844 & start & 11 & associate & 8 & marry & 6 \\
\hline 9 & start & 1641 & chat & 10 & communicate & 8 & do & 6 \\
\hline 10 & live & 1613 & compete & 7 & go & 8 & be & 6 \\
\hline
\end{tabular}


Table 4. Correlations ( $r$-values) for verb usage in selected VACs between learner groups ( $p$-value for all correlations: $<0.01)$

\begin{tabular}{lllll}
\hline Comparison & V about $\mathbf{n}$ & V for $\mathbf{n}$ & V in $\mathbf{~}$ & V with $\mathbf{~}$ \\
\hline $\begin{array}{l}\text { ICLE Turkish vs. } \\
\text { ICLE German }\end{array}$ & 0.79 & 0.68 & 0.59 & 0.65 \\
$\begin{array}{l}\text { ICLE Turkish vs. } \\
\text { ICLE Spanish }\end{array}$ & 0.76 & 0.71 & 0.62 & 0.55 \\
$\begin{array}{l}\text { ICLE German vs. } \\
\text { ICLE Spanish }\end{array}$ & 0.83 & 0.75 & 0.62 & 0.60 \\
\hline
\end{tabular}

Figure 1: Correlation of verbs in ICLE Turkish and ICLE German for 'V about n'

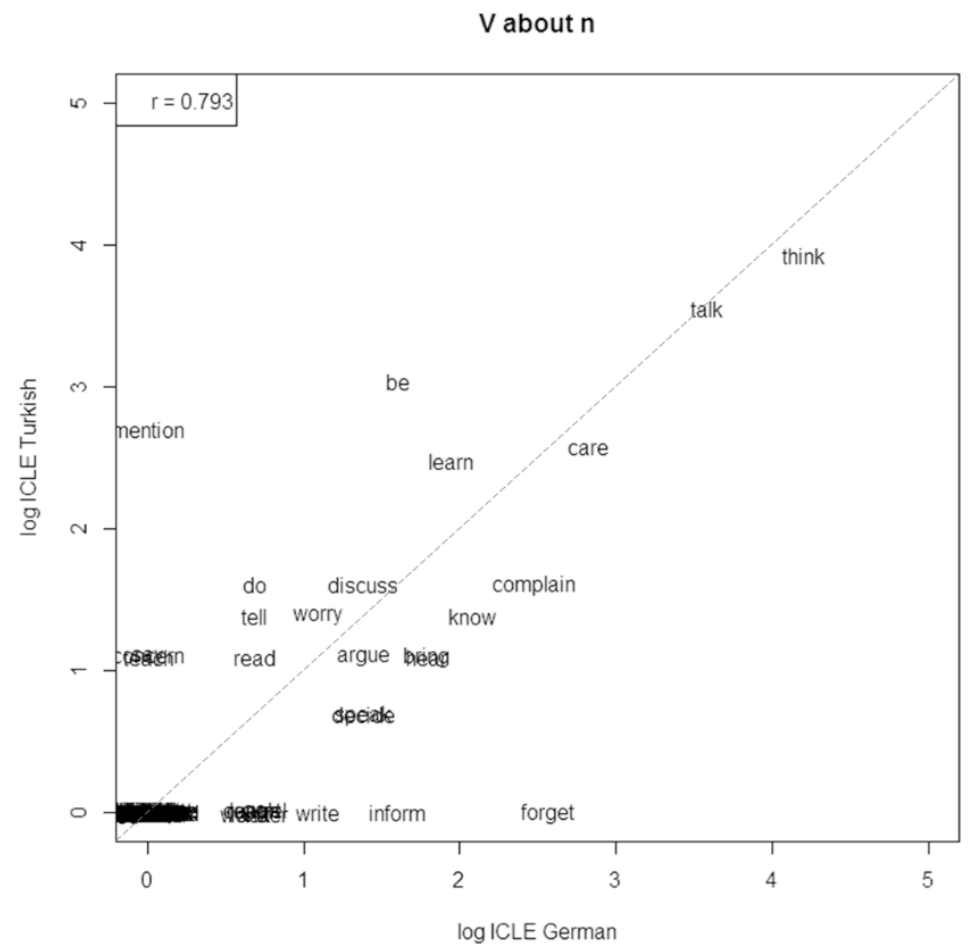

4.3 Examining the influence of native English usage on VACs in Turkish learner English

The correlation analysis of verb distributions across corpora also helped us to address RQ 3 and measure how strongly Turkish learners' VAC production is influenced 
by L1 usage. Table 5 provides the $r$-values for comparisons of verb distributions in our four focus VACs between ICLE subsets and the BNC. Overall, $r$-values for these comparisons are much lower than for those discussed in the previous section. This is due to a large extent to the $\mathrm{BNC}$-derived lists being much longer than those retrieved from the ICLE subsets. The result of this was that we included a large number of BNC verbs (data points) in our comparisons for which there were no occurrences in ICLE Turkish/German/Spanish.

However, we still see that, especially for 'V about n' and 'V for n', correlations between learner verb-in-VAC production and verbs-in-VACs in usage are not trivial. Correlation values between 0.40 and 0.60 indicate that learners are indeed influenced by frequencies in usage and that their verb-VAC associations overlap with those of L1 speakers. The scatterplot for ' $\mathrm{V}$ about n' in Figure 2 illustrates that a large number of verbs that occur in this VAC in the BNC are also used by ICLE Turkish writers, even though not with the same relative frequencies. Like L1 speakers, Turkish learners frequently use verbs such as THINK, TALK, BE, CARE, and LEARN in this construction. The plot also confirms that one of the few verbs that occurs comparatively more often in this VAC in ICLE Turkish than in the BNC (plotted above the diagonal) is DIscuss.

For ' $\mathrm{V}$ in n' and ' $\mathrm{V}$ with n', verb distributions in ICLE Turkish are less similar to those in the BNC, as reflected by the somewhat lower correlation values. This may point to difficulties Turkish learners experience with the appropriate use of the prepositions in and with. The bottom plot in Figure 2 visualizes the correlation between ICLE Turkish and BNC verbs used in ' $\mathrm{V}$ in n'. Compared to the plot for ' $\mathrm{V}$ about n', verbs here are plotted closer to the x-axis and further away from the diagonal indicating that Turkish learners' verb associations for this VAC are less in line with L1 usage than those for 'V about n'. The plot also highlights a verb we already commented on in the discussion of top-10 verbs for ' $\mathrm{V}$ in n' (Table 3), CHEAT, which is plotted above the diagonal because it is markedly more frequent in ICLE Turkish than in the BNC data. The influence of $\mathrm{L} 1$ usage on learner verb-VAC associations is fairly similar across learner groups for ' $\mathrm{V}$ in n' (see $r$-values in Table 5). For the three other focus VACs we observe slightly more variation with ICLE German having higher $r$-values than ICLE Turkish and ICLE Spanish for 'V about n' and 'V for n'. For 'V with n' the ICLE Turkish-BNC correlation is stronger than that between the other two ICLE subcorpora and the BNC. 
Table 5. Correlations ( $r$-values) for verb usage in selected VACs between learner groups and L1 usage

\begin{tabular}{lcccc}
\hline Comparison & V about $\mathbf{n}$ & V for $\mathbf{n}$ & V in $\mathbf{n}$ & V with $\mathbf{~}$ \\
\hline $\begin{array}{l}\text { ICLE Turkish vs. } \\
\text { BNC }\end{array}$ & 0.49 & 0.40 & 0.37 & 0.36 \\
$\begin{array}{l}\text { ICLE German vs. } \\
\text { BNC }\end{array}$ & 0.60 & 0.49 & 0.39 & 0.33 \\
$\begin{array}{l}\text { ICLE Spanish vs. } \\
\text { BNC }\end{array}$ & 0.56 & 0.42 & 0.37 & 0.28 \\
\hline
\end{tabular}

Figure 2. Correlations of verbs in ICLE Turkish and BNC for 'V about n' (top plot) and 'V in n' (bottom plot)

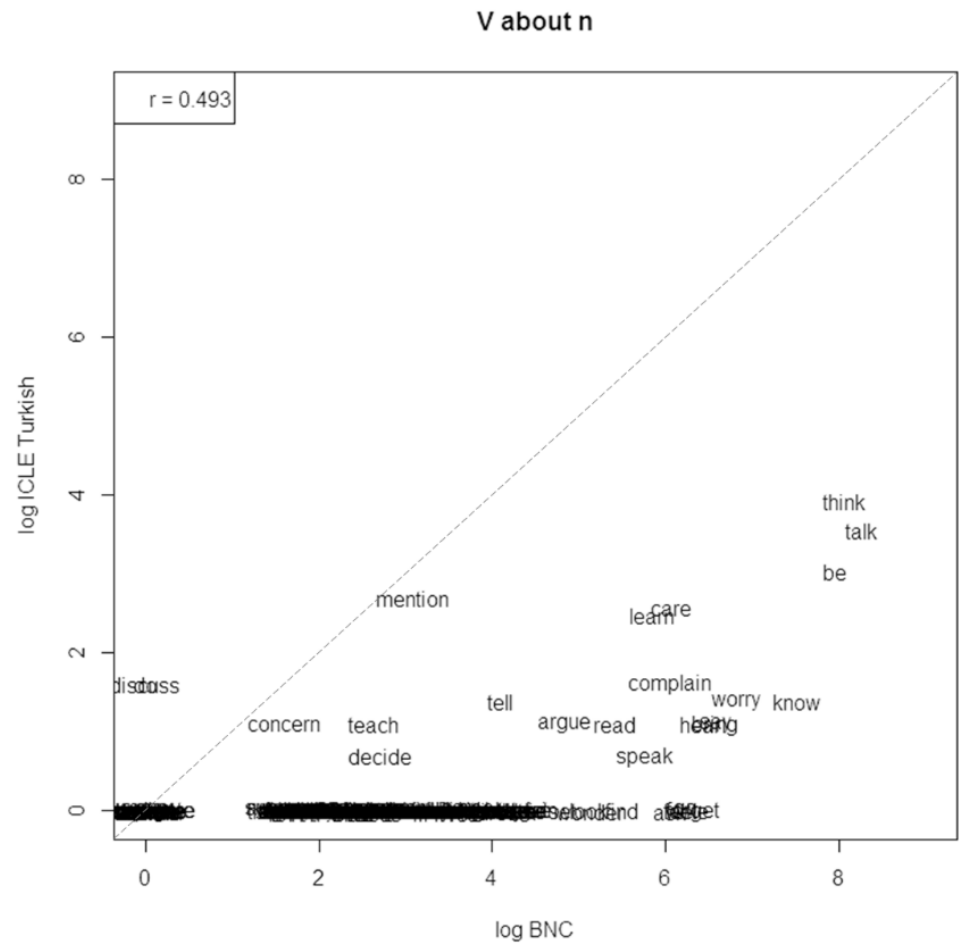




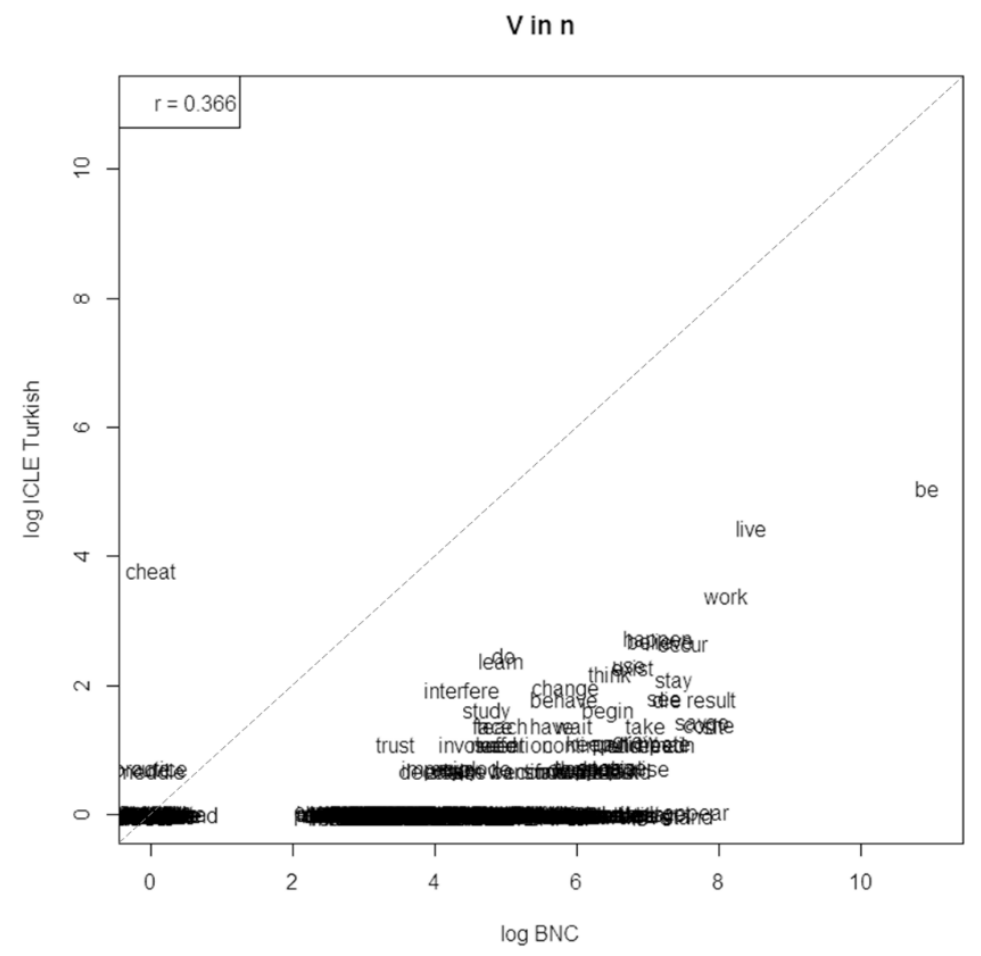

\subsection{L1 Turkish transfer effects on Turkish learners' use of English VACs}

In order to address our fourth and final research question, we examined whether certain verb-VAC association patterns that were found in Turkish learner writing could be the result of crosslinguistic transfer from Turkish, the learners' L1. We did this by extracting translation equivalents of selected verbs and prepositions from the Turkish National Corpus (TNC), and also by analyzing ICLE and BNC concordances of selected VACs in more detail.

Starting with 'V about n', we noted that MENTION was among the most strongly associated verbs in this VAC in ICLE Turkish. An ICLE concordance analysis shows that 'mention about' is used altogether 15 times by 14 different student writers in the ICLE Turkish subcomponent. It also shows that of all ICLE writers only two others (one in ICLE Chinese and one in ICLE Polish) use this combination. The 100-million word BNC contains 22 instances of this verb-VAC combination, 14 of which occur in the spoken and the remaining eight in (non-academic) written English. The high frequency of 'mention about' in ICLE Turkish has three possible explanations. First, given that 'mention about' is more common in speech than in writing, the finding may point to a limited register awareness of the L1Turkish writers. Another explanation 
would be a tendency of the learners to overgeneralize which verbs are appropriate choices for this VAC and select a verb (MENTION) that is semantically similar to verbs that fit the construction well (including taLK, THINK, WRITE, and ARGUE). Lastly, L1 influence could be another factor. In Turkish, a postposition -den (from) is attached to a noun (the argument) that precedes the verb MENTION. In the TNC example 'üç evreden bahset-' (three phasestfrom mention), the writer expresses the meaning 'mention three phases'. We counted 838 instances of this 'argument+postposition verb' construction only in the academic subset of the TNC. The frequency of this construction and the general presence of complex verb-adposition patterns in Turkish usage (see also Jensen, 2014; Çabuk, 2009; Özışık, 2014) may lead to Turkish learners adding in prepositions in English where they are not required or even lead to unidiomatic expressions. The last two of these reasons could also explain the repeated use of 'discuss about' by Turkish learners (five instances in four different student essays). Like 'mention about' it can be a semantic extension of core exemplars of the VAC, as well as the result of preposition overuse. There are two equivalent constructions in Turkish: 'noun+-la/le ilgili tartı̧̧-' (noun+with about discuss) and 'noun hakkında tartıs.' (noun about discuss). Even though we were only able to find a handful of examples of each in the TNC, their existence in their L1 may have affected our Turkish learner writers.

Another interesting observation we made on VACs in ICLE Turkish was the comparatively high frequency of ' $\mathrm{V}$ in n', the most common of the 19 analyzed VACs in terms of overall token number. This could be in part the result of learners overusing in (also reported by Çabuk 2009) because in serves as a translation equivalent of several lexicogrammatical items (case markers, adpositions) in Turkish due to its morphological richness being an agglutinative language (Durrant, 2013). Our analysis of the ICLE Turkish ' $\mathrm{V}$ in n' concordance brought to light several unidiomatic or erroneous uses of this construction, a sample of which we included in Table 6. We can argue that these examples are the result of crosslinguistic transfer from Turkish where translation equivalents of in often combine with nouns. For example, Turkish 'şüphe içinde' ('hesitation in(locative) inside of') might explain the learner's production of 'be in hesitation' in English. The absence of a verb marker in Turkish may also explain the frequent use of forms of the semantically bleached verb BE in the examples in Table 6 . 
Table 6. Unidiomatic uses of ' $\mathrm{V}$ in n' in ICLE Turkish

\begin{tabular}{rll}
\hline Left context & Node $(\mathrm{V}$ in) & \multicolumn{1}{c}{ Right context $(\mathrm{n})$} \\
\hline $\begin{array}{r}\text { or a place where the } \\
\text { parents } \\
\text { she }\end{array}$ & is in & the teacher's authority \\
they & may be in & lack of money \\
hesitation to go out & desire for big amounts of \\
if anybody & becomes in & a difficult position \\
people & come in & a point that \\
they & survive in & Life \\
money & will talk in & Everywhere \\
\hline
\end{tabular}

One of the verbs frequently used in ' $\mathrm{V}$ in n' in ICLE Turkish but less so in ICLE German, ICLE Spanish, and the BNC was EXIST. A possible reason for this is again crosslinguistic transfer from Turkish where the verb has several approximate translations with a wide range of usages. The most common translation attested in the TNC is 'var ol-' which literally means 'existent become'. In addition to expressing 'exist', 'var ol'- is also used to express the meaning 'there BE' (existential use; Göksel \& Kerslake, 2005, p. 111) with 'ol-' serving as a support verb or light verb which does not carry much meaning itself (SØodowicz, 2007; Uçar, 2010). This means that an L1 Turkish learner of English may use forms of EXIST instead of using the more common structure 'there BE'. 'Var ol-' along with other similar forms and their inflections (var, vardır, varsa, mevcut, mevcuttur) is highly frequent in the TNC (2,456 instances per million words). In our discussion of the verb lists in Table 3, we also highlighted the verb CHEAT as occurring unusually frequently in ' $\mathrm{V}$ in n' in ICLE Turkish. A concordance analysis shows that the 44 instances of 'cheat in' appear in 24 different learner argumentative essays on the value of university degrees. In these essays learners talk about students cheating in tests or exams. The frequent use of 'cheat in' hence appears to be the result of a task effect.

A final verb we would like to discuss is STRUGGLE which appeared in the top-10 lists for ' $V$ with n' and ' $V$ for n' in ICLE Turkish but not in those for the other corpora we included in our analysis. The comparatively high frequencies of both 'struggle with' (12 times in eight learner texts) and 'struggle for' (nine times in nine texts) again appear to be the result of L1 Turkish crosslinguistic transfer. A common Turkish translation 
equivalent of 'struggle with' is 'noun+-le/-la mücadele et'- ('noun+with struggle practice'). The verb phrase 'mücadele et'' conveys the literal meaning of 'doing or practicing struggle'. Among 1,488 instances of mücadele in the academic subsection of the TNC, we found 111 examples of the construction. Among the most frequent collocates of mücadele in the TNC we also found the Turkish translation equivalent of for (için). A search for the construction 'noun için mücadele et-' ('noun+for struggle do/practice') retrieved 56 results in the academic subsection of the TNC. While this constitutes evidence of collocational transfer from the learners' L1, we need to keep in mind that, given the typological differences between the two languages, none of the 19 English VACs included in our study have clear one-to-one correspondences in Turkish, which means that our TNC analysis is not exhaustive, despite its level of detail.

\section{Conclusion and outlook}

Following recent research that looks at learner knowledge of verb constructions from a usage-based perspective and responding to the scarcity of research on patterns in L1 Turkish learner English, the goal of this study was to gain a better understanding of what Turkish learners know about a selection of frequent VACs in English and whether/how their production of these VACs is affected by L2 usage and L1 transfer. The research questions we addressed were:

RQ 1: How productive and how predictable are selected VACs in Turkish learner English compared to German and Spanish learner English?

RQ 2: In terms of dominant verb-VAC associations, do selected VACs in Turkish learner English differ from those in German and Spanish learner English? If so, in what ways?

RQ 3: Is the distribution of verbs in a set of high-frequency VACs in Turkish learner English influenced by English usage? Is this potential influence of usage stronger for Turkish than for German and Spanish learners?

RQ 4: Are there any noticeable effects of the first language on Turkish learners' use of English VACs?

To address RQ 1, we determined type-token ratios (TTRs) and normalized entropy values $\left(\mathrm{H}_{\text {norm }}\right)$ for all verbs used in 19 different VACs in ICLE Turkish and compared them against TTR and $\mathrm{H}_{\text {norm }}$ values for the same VACs in ICLE German and ICLE Spanish (using the BNC as a reference dataset). We found that type and token frequencies vary considerably across VACs in ICLE Turkish and that only a small subset 
of the 19 constructions provide high enough token numbers for systematic quantitative analyses. Of those high-frequency VACs, 'V for n' and 'V with n' have particularly high TTR values which means that they are more productive in the Turkish learner data than other VACs (e.g. 'V about n'). The German and Spanish learner data show similar trends, although with a tendency for ICLE Spanish VACs to be more productive than VACs in ICLE Turkish and ICLE German. The comparisons of entropy scores across datasets revealed that verb distributions in VACs in Turkish learner writing tend to be considerably less predictable (and more even) than in L1 usage, reflected by higher $\mathrm{H}_{\text {norm }}$ values in ICLE Turkish than in the BNC. The entropy analysis also indicated that for a range of VACs Turkish learners also show lower predictability (and less Zipfian verb-in-VAC distributions) than their Spanish and German peers.

In response to RQ 2, we compared dominant verb-VAC associations for four highfrequency VACs between ICLE Turkish, ICLE German, and ICLE Spanish (with the BNC used for reference purposes). The focal VACs were 'V about n', 'V for n', 'V in n', and ' $V$ with n'. While we observed some overlap in the most commonly used verbs in these VACs across datasets (e.g. DEAL, AGREE, LIVE, and BE in 'V with n'), we also noted several marked differences between learner production and native usage data, as well as verb choices that appear to be L1 Turkish specific. Examples include associations between ' $\mathrm{V}$ about n' and the verbs MENTION and DISCUSS, 'V for n' and the verbs STUdy, STRUGGLE, and DO, 'V in n' and the verb CHEAT, and 'V with n' and the verbs STRUGGLE, CHAT, and COMPETE. Results from a correlation analysis which allowed us to systematically compare how similar or different verb distributions in a VAC are between two learner groups (e.g. L1 Turkish vs. L1 German) allowed us to further address RQ2. It showed that for 'V for n' and 'V in n' Turkish learners' verb distributions are closer to those of Spanish learners whereas when it comes to ' $\mathrm{V}$ about n' and 'V with n' Turkish learners correlate more with German than Spanish learners in their verb choices. Overall, we did not observe any clear language typology related patterns (between Turkish and Spanish as verb-framed languages on the one hand and German as a satellite-framed language on the other) but instead fairly high correlation values across all three L1 groups for the four focus VACs.

Correlation values and scatterplots that visualize the overlap in verb preferences between two datasets also enabled us to address RQ 3. We found that L1 Turkish learners are sensitive to verb-in-VAC distributions in native usage and do not randomly pick verbs as slot fillers in a construction. This is particularly true for ' $\mathrm{V}$ about n' and 'V for n'. While the scatterplots show which of the verbs that are frequent in a VAC in usage also occur in the same VAC in ICLE Turkish, they also highlight verbs that are comparatively more frequent in Turkish learner production than in usage. Through concordance searches in the Turkish National Corpus we were able to gather evidence 
to confirm that a likely reason for verb-VAC association patterns that deviated from native usage was crosslinguistic transfer from the learners' L1. This allowed us to respond to RQ 4 with an affirmative 'yes'.

To summarize our findings, we can say that the intermediate-to-advanced Turkish learners who contributed writing samples to ICLE have strong verb-constructional knowledge that is influenced in systematic ways both by native English (L2) usage and by typological and collocational patterns in Turkish (L1). Our findings only partially confirm typological similarities between Turkish and Spanish (both being verb-framed) and point to a more complex picture in which additional morphological aspects (not just the way in which path and manner of motion are expressed) play a role, and which affects L1 Turkish learner production of VACs. Verb framing alone does not explain the patterns of verb-in-VAC usage of this learner group; other lexicogrammatical patterns in Turkish as well as learners' creative semantic expansions of VACs (with near-synonyms of core verbs) also seem to play an important role. These findings support previous research on not only the expression of motion by Turkish learners (Babanoğlu, 2018; Demirtaş, 2010; Duruk, 2016; Durun, 2015; D. Yilmaz, 2018; İşler, 2014), but also on the challenges Turkish learners face in using English prepositions appropriately (Çabuk, 2009; Özışık, 2014), a problem they share with speakers of English as Lingua Franca (Cogo \& Dewey, 2010; Seidlhofer, 2004). In our opinion, the creative use of verbs that are semantically related to central verbs in a VAC but not necessarily idiomatic choices, provides further evidence for the discursive hybridity (Mauranen, Perez-Llantada \& Swales, 2010; Pérez-Llantada, 2014) of second language writing in which the 'constructicons' of a speaker's first and second language intersect.

Despite the insights it provided, our study has a number of remaining limitations that ought to be addressed in future research on usage-based SLA. The only source of L1 Turkish learner data available to us was ICLE Turkish, which consists exclusively of argumentative essays by intermediate and advanced college level EFL learners and is fairly small by today's standards (we noted in Section 4.1 that only four of our 19 VACs were well attested in ICLE Turkish). It would be valuable to carry out a similar analysis of VACs in corpora of spoken Turkish learner English, larger corpora of written Turkish learner English (ideally capturing a variety of text types), and in longitudinal or cross-sectional corpora that capture Turkish learner English (spoken and written) produced at different proficiency levels. This would allow us to describe not just what intermediate and advanced learners know about VACs but also how this knowledge develops over time. Given the scarcity of existing studies, we would also like to see more research that examines additional constructions in language produced by Turkish learners and learners of other non-European L1s. Our data analysis was limited to a set of 19 VACs of the 'verb plus preposition plus noun (phrase)' type 
so our findings may not be representative of Turkish learners' VAC knowledge in general. Expanding this line of research to other types of constructions would hence be extremely valuable. Since some of our previous research on L1 German and L1 Spanish learner knowledge of VACs has highlighted the benefits of combining corpus data with psycholinguistic evidence (Ellis, Römer \& O’Donnell, 2016; Römer, Roberson, O’Donnell \& Ellis, 2014; Römer, Skalicky \& Ellis, 2018), we think that adding an experimental component would strengthen studies on L1 Turkish learner VACs. Finally, while our concordance searches in a Turkish reference corpus (the TNC) led to important insights that helped with the interpretation of some of our findings, it was not exhaustive in that it did not include all possible translation equivalents of English VACs. Future work on learner constructions would benefit from taking a more systematic contrastive approach including analyses of the learner's L1, their L2, and their interlanguage (Gilquin, 2001; Granger, 1996), as it will help uncover sources of marked VAC usage by learners. We look forward to seeing future research that addresses some of these open tasks, all of which we believe will help us to even better understand how second language learners acquire English verb-argument constructions.

\section{References}

Aksan, Y., \& Aksan, M. (2009) Building a national corpus of Turkish: Design and implementation (Vol. 3, pp. 299-310). Working Papers in corpus-based linguistics and language education.

Aksan, Y., Aksan, M., Koltuksuz, A., Sezer, T., Mersinli, Ü., Demirhan, U. U., Yilmazer, H. \& Kurtoglu, Ö., Atasoy, G., Öz, S., Y1ldız, İ. (2012) Construction of the Turkish National Corpus (TNC). In Proceedings of the 8th International Conference on Language Resources and Evaluation (pp. 3223-3227) (LREC 2012). Turkey: Istanbul. http://www.lrec-conf.org/proceedings/lrec2012/papers.html.

Allen, S., Özyürek, A., Kita, S., Brown, A., Furman, R., Ishizuka, T., \& Fujii, M. (2007) Language-specific and universal influences in children's syntactic packaging of manner and path: A comparison of English, Japanese, and Turkish. Cognition, 102(1), $16-48$.

Beavers, J., Levin, B., \& Tham, S. W. (2010) The typology of motion expressions revisited. Journal of Linguistics, 46(2), 331-377.

Burnard, L. (2007) Reference Guide for the British National Corpus (XML edition). Retrieved from: http://www.natcorp.ox.ac.uk/docs/URG.

Çabuk, S. (2009) The Use of Prepositions in Second Language Acquisition Process (Unpublished Master's Dissertation, Middle East Technical University). 
Cadierno, T. (2008) Learning to talk about motion in a foreign language. In P. Robinson \& N.C. Ellis (Eds.) Handbook of cognitive linguistics and second language acquisition (pp. 239-275). New York: Routledge.

. (2013) Thinking for speaking in second language acquisition. In C. A. Chapelle (ed.), The Encyclopedia of Applied Linguistics. Malden, MA: Wiley-Blackwell. Accessed 11 May 2018 at http://onlinelibrary.wiley.com/doi/10.1002/9781405198431. wbeal1213/full.

Cogo, A., \& Dewey, M. (2012) Analysing English as a lingua franca: A corpus-driven investigation. Bloomsbury Publishing.

Durrant, P. (2013) Formulaicity in an agglutinating language: The case of Turkish. Corpus Linguistics and Linguistic Theory, 9(1), 1-38.

Duruk, E. (2016) Turkish EFL Learners' Naming Motion Events in English. International Journal of English Language Teaching 4(1). 47-55.

Durun, E. (2015) Turkish EFL Learners Naming Motion Events in English. International Journal of English Language Teaching. 4 (1), 47-55.

Eeg-Olofsson, M., \& Altenberg, B. (1994) Discontinuous recurrent word combinations in the London-Lund Corpus. In U. Fries, G. Tottie, \& P. Schneider (Eds.), Creating and Using English Language Corpora: Papers from the Fourteenth International Conference on English Language Research on Computerized Corpora. Amsterdam: Rodopi, 63-77.

Ellis, N. C., \& Ferreira-Junior, F. (2009) Constructions and their acquisition: Islands and the distinctiveness of their occupancy. Annual Review of Cognitive Linguistics, 7, 188-221.

Ellis, N. C. \& O’Donnell, M. B. (2014) Construction learning as category learning: A cognitive analysis. In T. Herbst, H.J. Schmid, \& S. Faulhaber (Eds.), Constructions Collocations Patterns. Berlin: De Gruyter Mouton, 71-97.

Ellis, N. C., O’Donnell, M. B., \& Römer, U. (2014) Second language processing of verb-argument constructions is sensitive to form, function, frequency, contingency, and prototypicality. Linguistic Approaches to Bilingualism, 4(4), 405-431.

Ellis, N. C., Römer, U., \& O’Donnell, M. B. (2016) Usage-based Approaches to Language Acquisition and Processing: Cognitive and Corpus Investigations of Construction Grammar. Malden, MA: Wiley.

Eskildsen, S. W., \& Cadierno, T. (2007) Are recurring multi-word expressions really syntactic freezes? Second language acquisition from the perspective of usagebased linguistics. In M. Nenonen \& Niemi, S. (Eds.). Collocations and Idioms 1. Papers 
from the First Nordic Conference on Syntactic Freezes (Vol. 41). Joensuu, Finland: Joensuu University Press, 86-99.

Francis, G., Hunston, S., \& Manning, E. (1996) Grammar patterns 1: Verbs. London: HarperCollins.

Gass, S., \& Selinker, L. Eds. (1983) Language transfer in language learning. Rowley, MA: Newbury House.

Gilquin, G. (2001) The Integrated Contrastive Model Spicing up your data. Languages in Contrast 3 (1), 95-123.

Göksel, A., \& Kerslake, C. (2005). Turkish: A comprehensive grammar. London: Routledge.

Goldberg, A. E. (1995) Constructions: A construction grammar approach to argument structure. Chicago, IL: University of Chicago Press.

. (2003) Constructions: a new theoretical approach to language. Trends in Cognitive Sciences, 7(5), 219-224.

. (2006) Constructions at work. The nature of generalization in language. Oxford: Oxford University Press.

Goldberg, A. E., \& Casenhiser, D. 2008. Construction learning and second language acquisition. In P. Robinson \& N.C. Ellis (Eds.), A handbook of cognitive linguistics and SLA . Mahwah, NJ: Erlbaum. 197-215.

Granger, S. (1996) From CA to CIA and back: An integrated approach to computerized bilingual and learner corpora. In K. Ajmer, B. Altenberg, \& M. Johansson (Eds.), Languages in contrast. Text-based cross-linguistic studies. Lund, Sweden: Lund University Press. 37-51.

Granger, S., Dagneaux, E., Meunier, F., \& Paquot, M. (2009) International Corpus of Learner English. Louvain, Belgium: Presses Universitaires de Louvain.

Gries, S. T. \& Ellis, N. C. (2015) Statistical measures for usage-based linguistics. Language Learning, 65(S1), 228-255.

Hilpert, M. 2014. Construction grammar and its application to English. Edinburgh, UK: Edinburgh University Press.

İşler, Z. N. (2014) EFL Learner' Use of Path Elements in Motion Event Expressions: A Study on Turkish University Students (Unpublished Doctoral Dissertation). Middle East Technical University, Ankara, Turkey.

Jarvis, S. (2011) Conceptual transfer: Crosslinguistic effects in categorization and construal. Bilingualism: Language and Cognition 14(Special Issue). 1-8. 
.2013. Crosslinguistic influence and multilingualism. In Carol A. Chapelle (ed.), The encyclopedia of applied linguistics. Malden, MA: Wiley-Blackwell. Accessed 11 May 2018 at http://onlinelibrary.wiley.com/doi/10.1002/9781405198431. wbeal0291/full.

Jarvis, S., \& Pavlenko, A. (2008) Crosslinguistic influence in language and cognition. New York: Routledge.

Kumar, U., Kumar, V., \& Kapur, J. N. (1986) Normalized measures of entropy. International Journal of General Systems, 12(1), 55-69.

Mauranen, A., Perez-Llantada, C, \& Swales, J. M. (2010) Academic Englishes: A standardized knowledge? In A. Kirkpatrick (Ed.), The Routledge Handbook of World Englishes. London: Routledge. 634-652.

Pérez-Llantada, C. (2014) Formulaic language in L1 and L2 expert academic writing: Convergent and divergent usage. Journal of English for Academic Purposes, 14, 84-94.

Özdemir, M. 2011). Yabanci dil olarak Türkçe öğretiminde edatlar (Unpublished Master's Dissertation). Istanbul University, Istanbul, Turkey.

Özışık, C. (2014) Identifying preposition errors of Turkish EFL students. ELT Research Journal, 3(2), 59-69.

Özyürek, A., \& Kita, S. 1999. Expressing manner and path in English and Turkish: Differences in speech, gesture, and conceptualization. In M. Hahn, \& S.C. Stoness (Eds.), Twenty-first Annual Conference of the Cognitive Science Society. New Jersey: Lawrence Erlbaum Associates. 507-512.

Özyürek, A., \& Ozcaliskan, S. (2000) How do children learn to conflate manner and path in their speech and gestures? Differences in English and Turkish. In E.V. Clark (Ed), The Proceedings of the 30th Stanford Child Language Research Forum. CSLI Publications. 77-85.

Özyürek, A., Kita, S., Allen, S., Brown, A., Furman, R., \& Ishizuka, T. (2008) Development of Cross-Linguistic Variation in Speech and Gesture: Motion Events in English and Turkish. Developmental Psychology, 44(4), 1040-1054.

R Development Core Team. (2012) R: A language and environment for statistical computing. Vienna, Austria: R Foundation for Statistical Computing.

Römer, U., \& Garner, J. R. Under review. The development of verb constructions in spoken learner English: Tracing effects of usage and proficiency.

Römer, U., O’Donnell, M. B., \& Ellis, N. C. (2014) Second language learner knowledge of verb-argument constructions: Effects of language transfer and typology. The Modern Language Journal, 98(4), 952-975. 
Römer, U., Roberson, A., O’Donnell, M. B., \& Ellis, N. C. (2014). Linking learner corpus and experimental data in studying second language learners' knowledge of verb-argument constructions. ICAME Journal, 38(1), 59-79.

Römer, U., Skalicky, S., \& Ellis, N. C. (2018) Verb-argument constructions in advanced L2 English learner production: Insights from corpora and verbal fluency tasks. Corpus Linguistics and Linguistic Theory. DOI: https://doi.org/10.1515/cllt-20160055.

Seidlhofer, B. (2004) 10. Research perspectives on teaching English as a lingua franca. Annual Review of Applied Linguistics, 24, 209-239.

Slobin, D. I. (2004) The many ways to search for a frog: Linguistic Typology and the expression of motion events. In S. Strömqvist \& L. Verhoeven (Eds.), Relating events in narrative: Vol. 2. Typological and contextual perspectives. Mahwah, NJ: Lawrence Erlbaum Associates. 219-257.

Słodowicz, S. (2007) Complement Control in Turkish. ZAS Papers in Linguistics, 47, 125-157.

Talmy, L. (2000) Toward a cognitive semantics: Typology and process in concept structuring. Cambridge, MA: MIT Press.

Toplu, A. B. (2011) Linguistic expression and conceptual representation of motion events in Turkish, English and French: An experimental study. (Unpublished PhD Dissertation). Middle East Technical University, Ankara. 
